\title{
Management options for the treatment of benign prostatic hyperplasia with or without erectile dysfunction: a focus on tadalafil and patient considerations
}

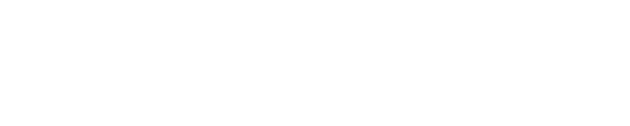

\section{Bader Alsaikhan \\ Khalid Alrabeeah \\ Serge Carrier}

McGill University Health Centre, Montreal, Quebec, QC, Canada
Correspondence: Serge Carrier Jewish General Hospital, E-939, 3755 Côte Ste-Catherine Road, Montréal, Québec H3T IE2, QC, Canada Email: serge.carrier@mcgill.ca

\begin{abstract}
Lower urinary tract symptoms (LUTS) and erectile dysfunction increase with age. Several studies have identified a true association between these two disorders. Basic research studies have shown a significant decrease in the nitric oxide/cyclic guanosine monophosphate pathway with age that leads to decreased relaxation of the bladder wall and prostate and worsening LUTS. In this review article, we will focus on the potential use and clinical significance of phosphodiesterase-5 inhibitors in the treatment of LUTS secondary to benign prostate hyperplasia.
\end{abstract}

Keywords: lower urinary tract symptoms, phosphodiesterase-5 inhibitors

\section{Introduction}

Benign prostatic hyperplasia $(\mathrm{BPH})$ is the most common cause of lower urinary tract symptoms (LUTS) in adult males. LUTS vary in severity, ranging from mild to severe, affecting patients' quality of life (QoL) accordingly. Approximately 40\% of men by the age of 50 years and $80 \%$ of men by 80 years will have $\mathrm{BPH},{ }^{1}$ the symptoms of which include poor urinary stream, urinary hesitancy, feeling of incomplete bladder emptying, urgent and/or frequent urination, and urge incontinence.

Medical management of this condition has become the first-line therapeutic approach above surgical interventions. Agents include $\alpha$-adrenergic blockers, 5 - $\alpha$ reductase inhibitors, and phytotherapies, used alone or in combination. However, bothersome sexual side effects are known to be associated with these therapies.

Furthermore, the prevalence of erectile dysfunction (ED) also increases concomitantly with age. By the age of 40 years, $40 \%$ of men will experience some form of ED. ${ }^{2}$ ED has been observed to coexist with $\mathrm{BPH}$ and is more common as men age. ${ }^{3-7}$ In a multinational survey of aging males, LUTS were identified as a risk factor for ED. ${ }^{6}$ A Dutch survey on aging men demonstrated that severe LUTS were associated with ED and ejaculatory dysfunction. ${ }^{7}$ Both conditions can have a significant impact on patients' QoL. ${ }^{8}$

The pathophysiology of LUTS is not yet fully understood. However, reduction in nitric oxide/cyclic guanosine monophosphate (cGMP) signaling, hyperactivity of the RhoA/RhoA-kinase pathway, chronic pelvic ischemia, and autonomic hyperactivity have all been proposed as possible mechanisms of action. ${ }^{9}$ All of the aforementioned factors have been observed to be counteracted by the use of phosphodiesterase- 5 (PDE5) inhibitors (PDE5-Is). ${ }^{10}$ PDE5 is prevalent in the muscular part of the bladder 
neck, prostatic urethra, and prostate. ${ }^{11}$ The use of PDE5-Is was investigated as a means of increasing intracellular cGMP and hence promoting smooth muscle relaxation and vasodilation in urogenital tissue, alleviating both pathologies. ${ }^{12}$ In this article, we will discuss the role of PDE5-Is, mainly tadalafil, in the LUTS/ED population, focusing on the main therapeutic effects, patient perspectives and QoL, safety, adverse effects (AEs), and the current place of PDE5-Is in therapy.

\section{Methods}

In this nonsystematic review of the literature, a MEDLINE search was conducted using the MeSH terms "prostatic hyperplasia", "erectile dysfunction", "phosphodiesterase 5 inhibitors", and "lower urinary tract symptoms". A focus was made to include articles discussing the role of tadalafil specifically among other PDE5-Is. This article is not intended to guide the clinical practice, but rather to provide insight into the current literature about the role of PDE5-Is in the treatment of LUTS/ED, including efficacy studies; safety and tolerability issues; and patient-focused perspectives, including QoL, adherence and uptake, and patient satisfaction and acceptability.

\section{Tadalafil}

Tadalafil is a selective, long-acting cGMP-specific PDE5-I. ${ }^{13}$ PDE5 is present in the tissue and vasculature of the bladder neck, prostatic urethra, prostate, and corpus cavernosum ${ }^{14,15}$ and is implicated in the pathology of LUTS/ED. ${ }^{10,16}$ Furthermore, PDE5 was found to be expressed in the sacral spinal regions and micturition control areas. ${ }^{17}$ In an animal model of bladder hyperactivity secondary to bladder outlet obstruction, the administration of sildenafil helped alleviate bladder overactivity when administered intravenously and intrathecally, indicating possible neurologic involvement of this class of medications. ${ }^{17}$ In transurethral resection of the prostate specimens, cGMP and cAMP (cyclic adenosine monophosphate) were significantly higher in patients receiving tadalafil or udenafil than in the control group. ${ }^{18}$ In addition, tadalafil was found to increase cyclic nucleotide levels in the bladder, prostate, and corpus cavernosum tissue in vivo. ${ }^{11,19,20}$ These findings support the hypothesis that tadalafil, with which the increase in cGMP increases arterial smooth muscle relaxation, leads to improved erectile function in men suffering from ED. Furthermore, elevated cGMP levels are also implicated in smooth muscle relaxation in the bladder, urethra, and prostate, ${ }^{20-22}$ in addition to improved tissue oxygenation in prostatic stroma $\mathrm{a}^{20,22}$ and inhibition of prostatic stromal cell proliferation ${ }^{22,23}$ in the preclinical setting.

\section{Effect of PDE5-Is on LUTS/ED}

Several clinical trials have been conducted to investigate the role of PDE5-Is in the LUTS/ED population. ${ }^{9,24-26}$ The main outcomes of these trials have included the effect of therapy on the International Prostate Symptom Score (IPSS) and BPH Impact Index, used to track BPH symptomatology; International Index of Erectile Function (IIEF), reflecting male sexual function; and maximum urinary flow rate (Qmax). Gacci et al performed a meta-analysis of trials comparing, in the first part, PDE5-Is to placebo, and, in the second part, PDE5-Is with $\alpha$-blockers to $\alpha$-blockers alone. ${ }^{9}$ In another metaanalysis by Dong et al, the authors performed an analysis of trials comparing tadalafil specifically versus placebo. ${ }^{24}$ These studies generally included men with LUTS with or without ED, and included studies using different doses of some medications. In both, treatment with PDE5-Is resulted in significantly improved IPSS and IIEF scores compared to placebo (Table 1). Dong et al reported a statistically significant improvement in IPSS by a mean score reduction of 2.19 compared to placebo, in addition to statistically significant improvements in irritative and obstructive IPSS subscores, BPH Impact Index scores, and IPSS-QoL index, which is reflective of the degree to which a patient is affected by LUTS. ${ }^{24}$

Qmax was not found to be statistically significant in the pooled PDE5-Is and tadalafil analysis (Table 1). ${ }^{9}$ This might be explained by the global smooth muscle relaxation effect exerted by these therapeutic agents on the bladder neck, urethra, prostate, and bladder detrusor. However, Dong et $\mathrm{al}^{24}$ described a statistically significant improvement in Qmax in the tadalafil $5 \mathrm{mg}$ group but not with other doses, a result that was not found in the meta-analysis performed by Porst et al using the same dose but different selection criteria. ${ }^{25}$ Porst et al specifically selected sexually active patients with LUTS and concomitant ED, while Dong et al included patients with LUTS with or without ED. This selection bias might explain the difference in the significance of the change in Qmax after treatment. The absence of treatment effect on urodynamic measures was also demonstrated by the randomized controlled trial by Dmochowski et al, which demonstrated no impact with long-term use of tadalafil on bladder contractility using invasive and noninvasive urodynamics. ${ }^{26}$ Furthermore, no significant difference in post-void residual urine was demonstrated after treatment with tadalafil. ${ }^{25}$ These findings suggest a mechanism other than mechanical changes by which PDE5-Is exert their role in alleviating symptoms associated with LUTS, and which might be related to increased vascularity and reduction of ischemia by interference with the nitric oxide/cGMP pathway 
Table I Score differences and adverse effect profiles reported in meta-analyses comparing PDE5-Is to placebo and tadalafil to placebo

\begin{tabular}{|c|c|c|c|c|c|c|c|c|}
\hline & \multicolumn{4}{|c|}{ Gacci et al $^{9}$} & \multicolumn{4}{|c|}{ Dong et $\mathrm{al}^{24}$} \\
\hline & \multicolumn{2}{|l|}{ PDE5-Is } & \multicolumn{2}{|l|}{ Placebo } & \multicolumn{2}{|c|}{ Tadalafil } & \multicolumn{2}{|l|}{ Placebo } \\
\hline Number of patients & 1,879 & & 870 & & $\mid, 87$ & & 1,042 & \\
\hline Mean score difference & \multicolumn{4}{|c|}{ Score (P-value) } & \multicolumn{4}{|c|}{ Score ( $P$-value) } \\
\hline IPSS & \multicolumn{4}{|c|}{$-2.85(<0.000 I)$} & \multicolumn{4}{|c|}{$-2.19(<0.00001)$} \\
\hline IIEF & \multicolumn{4}{|c|}{$5.49(<0.0001)$} & \multicolumn{4}{|c|}{$4.66(<0.0000 I)$} \\
\hline Qmax & \multicolumn{4}{|c|}{-0.01} & \multicolumn{4}{|c|}{$0.34(0.07)$} \\
\hline IPSS-QoL & & & & & \multicolumn{4}{|c|}{$-0.35(<0.00001)$} \\
\hline BII & & & & & \multicolumn{4}{|c|}{$-0.49(<0.000 I)$} \\
\hline Adverse effect profile & \multicolumn{2}{|l|}{$\%$} & OR & $P$-value & \multicolumn{2}{|l|}{$\%$} & $\mathbf{R} \mathbf{R}$ & $P$-value \\
\hline Headache & 4.6 & 2.1 & 1.88 & 0.008 & 3.6 & 2.6 & 1.14 & 0.04 \\
\hline Dyspepsia & 3.1 & 0.8 & 1.85 & 0.029 & 3.3 & 0 & 11.38 & $<0.00001$ \\
\hline Back pain & 2.5 & 1.5 & 1.18 & 0.503 & 2.9 & 1.3 & 2.95 & $<0.0001$ \\
\hline GERD & 1 & 0.2 & 2.21 & 0.063 & 1.7 & 0 & 7.4 & 0.003 \\
\hline Flushing & 1.2 & 0.2 & 4.89 & 0.007 & & & & \\
\hline Overall & 16 & 6 & & & 12.6 & 4.8 & & \\
\hline
\end{tabular}

Note: Bold and italic fonts highlight statistically significant results reported in papers mentioned in the table.

Abbreviations: BII, Benign Prostatic Hyperplasia Impact Index; GERD, gastroesophageal reflux disease; IIEF, International Index of Erectile Function; IPSS, International Prostate Symptom Score; IPSS-QoL, IPSS quality of life index; OR, odds ratio; PDE5-Is, phosphodiesterase-5 inhibitors; Qmax, maximum urinary flow rate; RR, relative risk.

and by halting inflammatory and profibrotic changes related to the RhoA/RhoA-kinase pathway.

Patients' initial characteristics seem to affect the degree of benefit experienced after treatment with PDI5-Is. In a regression analysis of pooled data, Gacci et al found a statistically significant effect of age, baseline body mass index, and IPSS on the degree of improvement, and concluded that lower baseline age and body mass index and higher baseline IPSS resulted in more beneficial effects after treatment with PDE5-Is. ${ }^{9}$ Hence, their optimal patient would be a young, healthy male with higher initial IPSS. Prostate-specific antigen levels at baseline did not seem to affect the degree of benefit in the analysis performed by Porst et al. ${ }^{25}$

\section{Combination of $\alpha$-blockers and PDE5-Is}

$\alpha$-blockers are currently the first-line therapy in men with LUTS secondary to BPH who fail conservative measures. Coadministration of PDE5-1s along with $\alpha$-blockers has been proposed. ${ }^{27-33}$ However, many concerns have been raised regarding the potential drug-drug interaction leading to a critical decrease in blood pressure. There are several studies that have examined this issue. Kloner et al assessed the safety of combining tadalafil with two different $\alpha$-blockers in their double-blind, placebocontrolled, randomized crossover study. ${ }^{27}$ They evaluated the hemodynamic effects of doxazosin $8 \mathrm{mg}$ for 7 days followed by tadalafil $20 \mathrm{mg}$, tamsulosin $0.4 \mathrm{mg}$ for 7 days followed by tadalafil 10 and $20 \mathrm{mg}$. In the first part of the study, patients who took doxazosin plus tadalafil experienced a significant decrease in the mean maximal systolic blood pressure. Moreover, three patients experienced symptoms of dizziness that did not correlate to significant changes in blood pressure. In the second part of the study, there were no significant differences seen in systolic blood pressure when tamsulosin was combined with tadalafil versus tamsulosin alone. ${ }^{27}$ A study by Giuliano et al also showed no significant hemodynamic interaction between tadalafil $20 \mathrm{mg}$ in combination with alfuzosin daily. ${ }^{28}$

Further studies have also addressed the question of whether dual therapy with an $\alpha$-blocker and PDE5-Is would be superior to an $\alpha$-blocker alone for LUTS. Kaplan et $\mathrm{al}^{29}$ showed that combination of alfuzosin and sildenafil was superior to monotherapy for treating LUTS with ED. Patients were divided into three groups: alfuzosin $10 \mathrm{mg}$ daily, sildenafil $25 \mathrm{mg}$ daily, or both. The results showed that there was an improvement of IPSS in all three groups, but with the greatest statistically significant benefit in the combination group when compared to the other two groups $(P<0.03)$. Moreover, IIEF scores improved the most in those on combination therapy compared to those in the other two groups $(P=0.002) .{ }^{29}$ Bechara et $a^{30}$ studied the efficacy and safety of tamsulosin $0.4 \mathrm{mg}$ daily and tadalafil $20 \mathrm{mg}$ daily versus tamsulosin $0.4 \mathrm{mg}$ daily in a double-blind, crossover, randomized controlled study. The patients were randomized into receiving the combination therapy or tamsulosin for 45 days, and then switched to the other group for another 45 days. Although both groups showed improvements in IPSS and IPSS-QoL from baseline, the combination group showed more improvement in IPSS and IPSS-QoL. Moreover, IIEF 
was better in the combination group $(P<0.001)$. However, there were no differences between the two groups concerning improvements in both uroflowmetry Qmax and post-void residual urine. ${ }^{30}$

Singh et al evaluated the efficacy of combining tamsulosin $0.4 \mathrm{mg}$ /day with tadalafil $10 \mathrm{mg} /$ day versus each alone. ${ }^{31}$ This randomized, open-label study included 133 men with LUTS due to BPH for 6 months or more, previous to the study. In this three-armed study, combination therapy was found to be significantly superior to tadalafil monotherapy $(P<0.05)$, but not tamsulosin monotherapy, in reducing IPSS. Furthermore, combination therapy was superior to tamsulosin monotherapy in alleviating ED symptoms measured by IIEF-5 score. However, in IPSS-QoL assessment, combination therapy was better than either monotherapy $(-79.65 \% ; P<0.05){ }^{31}$

The abovementioned studies, along with others, ${ }^{32,33}$ demonstrate the efficacy of combination PDE5-Is and $\alpha$-blockers for the treatment of LUTS. Although the use of an $\alpha$-blocker combined with daily tadalafil $5 \mathrm{mg}$ seems promising, no randomized double-blind study has yet been published. It will be interesting to see whether efficacy would be increased, as two different mechanisms of action will interact, as long as this is not at the expense of increasing side effects. Further studies are warranted.

Other treatment combinations have also been described. Casabé et al studied the effect of combining tadalafil with finasteride, a 5-alpha reductase inhibitor in an international, randomized, double-blind trial. ${ }^{34}$ They found a significant improvement in IPSS, IPSS-voiding, IPSS-storage, and IIEF scores in the long term when used daily compared to finasteride with placebo. ${ }^{34}$

\section{Dosage selection}

Tadalafil has been used in different doses throughout the literature. However, in a dose-finding study, $5 \mathrm{mg}$ administered daily for 12 weeks provided a positive risk-benefit profile. ${ }^{35}$ In another long-term study, patients converted from $2.5 \mathrm{mg}$ to $5 \mathrm{mg}$ daily experienced a significant improvement in IPSS, while patients reduced from 10 or $20 \mathrm{mg}$ daily to $5 \mathrm{mg}$ did not experience any decrease in IPSS. ${ }^{36}$ These studies suggest that $5 \mathrm{mg}$ daily is the ideal dose of tadalafil. Although $2.5 \mathrm{mg}$ is likely to help patients with ED, it does not seem to alleviate BPH-related symptoms, so down-titration from $5 \mathrm{mg}$ to $2.5 \mathrm{mg}$ is not a good strategy in the treatment of BPH/LUTS.

Tadalafil has a unique pharmacokinetic profile among other PDE5-Is, with a longer half-life of 17.5 hours and up to 36 hours of efficacy. ${ }^{12,37}$ Tadalafil is mainly metabolized by the hepatic CYP3A to a conjugated catechol, which is mainly excreted in feces (61\%) and urine (36\%). ${ }^{37,38}$ Mild-to-moderate hepatic impairment in patients did not seem to have a major effect of the pharmacokinetics of the drug, ${ }^{37}$ but data for severe hepatic dysfunction are lacking. Renal impairment was found to result in a greater systemic exposure, and dose adjustment is therefore required in such cases. $^{37}$

\section{AEs and safety}

PDE5-Is are generally safe and well tolerated, with an extremely low serious AE profile when used properly. ${ }^{9,24,25}$ Reported AEs with the use of PDE5-Is were in the range of $12 \%-16 \%$ compared to placebo., ${ }^{9,24}$ The main side effects of PDE5-I use were reported to be headache, dyspepsia, back pain, gastroesophageal reflux, and flushing. ${ }^{9}$ Interestingly, flushing was not reported with the use of tadalafil, and back pain was significantly higher with tadalafil, which might be explained by the higher inhibitory effect of tadalafil on PDE-5 and PDE-11 pathways, which is present in the skeletal muscles. ${ }^{13,39}$

Caution is advised when prescribing tadalafil to the elderly population, as it is associated with systemic vasodilation that might result in a transient hypotension. ${ }^{12}$ Furthermore, all PDE5-Is are contraindicated with the concomitant use of nitrates. ${ }^{40}$ The use of $\alpha$-blockers with tadalafil has been observed to produce few hypotensive events; however, data are still deficient, such that the AE profile of combining the two medications in daily use cannot be confidently judged. ${ }^{41}$ Daily use of tadalafil $5 \mathrm{mg}$ has been associated with less side effects overall than pro re nata (as needed) use. Overall, Dong et al found that the rate of serious AEs after using tadalafil for LUTS/ED was $1.23 \%$ and not statistically significant from a placebo group, and that the rate of discontinuation secondary to $\mathrm{AE}$ was $3.6 \%$ compared to $1.6 \%$ for placebo. ${ }^{24}$

\section{Conclusion}

LUTS and ED share a common pathophysiology and are frequently associated with advanced age. PDE5-Is block the degradation of cGMP, allowing increased levels of smooth muscle relaxation of bladder, prostate, and urethra. The introduction of PDE5-Is has expanded the therapeutic options for patients suffering from BPH/LUTS with or without ED.

\section{Disclosure}

Dr Carrier has received grants/research support from and been on the advisory board or presented for Eli Lilly, CanadaPfizer, and Canada-Bayer. He has not received any financial gains through this work. 


\section{References}

1. Berry SJ, Coffey DS, Walsh PC, Ewing LL. The development of human benign prostatic hyperplasia with age. J Urol. 1984;132(3): 474-479.

2. Braun M, Wassmer G, Klotz T, Reifenrath B, Mathers M, Engelmann U. Epidemiology of erectile dysfunction: results of the 'Cologne Male Survey'. Int J Impot Res. 2000;12(6):305-311.

3. Feldman HA, Goldstein I, Hatzichristou DG, Krane RJ, McKinlay JB. Impotence and its medical and psychosocial correlates: results of the Massachusetts Male Aging Study. J Urol. 1994;151(1):54-61.

4. Li MK, Garcia LA, Rosen R. Lower urinary tract symptoms and male sexual dysfunction in Asia: a survey of ageing men from five Asian countries. BJU Int. 2005;96(9):1339-1354.

5. Rosen R, Altwein J, Boyle P, et al. Lower urinary tract symptoms and male sexual dysfunction: the multinational survey of the aging male (MSAM-7). Eur Urol. 2003;44(6):637-649.

6. Laumann EO, Paik A, Rosen RC. Sexual dysfunction in the United States: prevalence and predictors. JAMA. 1999;281(6):537-544.

7. Blanker MH, Bohnen AM, Groeneveld FP, et al. Correlates for erectile and ejaculatory dysfunction in older Dutch men: a community-based study. J Am Geriatr Soc. 2001;49(4):436-442.

8. Wei JT, Calhoun E, Jacobsen SJ. Urologic diseases in America project: benign prostatic hyperplasia. J Urol. 2005;173(4):1256-1261.

9. Gacci M, Corona G, Salvi M, et al. A systematic review and meta-analysis on the use of phosphodiesterase 5 inhibitors alone or in combination with $\alpha$-blockers for lower urinary tract symptoms due to benign prostatic hyperplasia. Eur Urol. 2012;61(5): 994-1003.

10. Andersson KE, de Groat WC, McVary KT, et al. Tadalafil for the treatment of lower urinary tract symptoms secondary to benign prostatic hyperplasia: pathophysiology and mechanism(s) of action. Neurourol Urodyn. 2011;30(3):292-301.

11. Fibbi B, Morelli A, Vignozzi L, et al. Characterization of phosphodiesterase type 5 expression and functional activity in the human male lower urinary tract. $J$ Sex Med. 2010;7(1 Pt 1): 59-69.

12. Curran MP. Tadalafil: in the treatment of signs and symptoms of benign prostatic hyperplasia with or without erectile dysfunction. Drugs Aging. 2012;29(9):771-781.

13. Wright PJ. Comparison of phosphodiesterase type 5 (PDE5) inhibitors. Int J Clin Pract. 2006;60(8):967-975.

14. Küthe A, Wiedenroth A, Mägert HJ, et al. Expression of different phosphodiesterase genes in human cavernous smooth muscle. J Urol. 2001;165(1):280-283.

15. Uckert S, Kuczyk MA. Cyclic nucleotide metabolism including nitric oxide and phosphodiesterase-related targets in the lower urinary tract. Handb Exp Pharmacol. 2011;202(202):527-542.

16. Uckert S, Stief CG, Mayer M, Jonas U, Hedlund P. Distribution and functional significance of phosphodiesterase isoenzymes in the human lower urinary tract. World J Urol. 2005;23(6):368-373.

17. Füllhase C, Hennenberg M, Giese A, et al. Presence of phosphodiesterase type 5 in the spinal cord and its involvement in bladder outflow obstruction related bladder overactivity. J Urol. 2013;190(4): 1430-1435.

18. Zhao C, Kim SH, Lee SW, et al. Activity of phosphodiesterase type 5 inhibitors in patients with lower urinary tract symptoms due to benign prostatic hyperplasia. BJU Int. 2011;107(12):1943-1947.

19. Uckert $\mathrm{S}$, Hedlund $\mathrm{P}$, Waldkirch $\mathrm{E}$, et al. Interactions between cGMPand cAMP-pathways are involved in the regulation of penile smooth muscle tone. World J Urol. 2004;22(4):261-266.

20. Uckert S, Sormes M, Kedia G, et al. Effects of phosphodiesterase inhibitors on tension induced by norepinephrine and accumulation of cyclic nucleotides in isolated human prostatic tissue. Urology. 2008;71(3): 526-530.

21. Oger S, Behr-Roussel D, Gorny D, et al. Combination of alfuzosin and tadalafil exerts an additive relaxant effect on human detrusor and prostatic tissues in vitro. Eur Urol. 2010;57(4):699-707.
22. Tinel H, Stelte-Ludwig B, Hütter J, Sandner P. Pre-clinical evidence for the use of phosphodiesterase-5 inhibitors for treating benign prostatic hyperplasia and lower urinary tract symptoms. BJU Int. 2006;98(6):1259-1263.

23. Uckert S, Küthe A, Jonas U, Stief CG. Characterization and functional relevance of cyclic nucleotide phosphodiesterase isoenzymes of the human prostate. J Urol. 2001;166(6):2484-2490.

24. Dong Y, Hao L, Shi Z, Wang G, Zhang Z, Han C. Efficacy and safety of tadalafil monotherapy for lower urinary tract symptoms secondary to benign prostatic hyperplasia: a meta-analysis. Urol Int. 2013;91(1):10-18.

25. Porst H, Roehrborn CG, Secrest RJ, Esler A, Viktrup L. Effects of tadalafil on lower urinary tract symptoms secondary to benign prostatic hyperplasia and on erectile dysfunction in sexually active men with both conditions: analyses of pooled data from four randomized, placebo-controlled tadalafil clinical studies. $J$ Sex Med. 2013;10(8): 2044-2052.

26. Dmochowski R, Roehrborn C, Klise S, Xu L, Kaminetsky J, Kraus S. Urodynamic effects of once daily tadalafil in men with lower urinary tract symptoms secondary to clinical benign prostatic hyperplasia: a randomized, placebo controlled 12-week clinical trial. J Urol. 2010;183(3): 1092-1097.

27. Kloner RA, Jackson G, Emmick JT, et al. Interaction between the phosphodiesterase 5 inhibitor, tadalafil and 2 alpha-blockers, doxazosin and tamsulosin in healthy normotensive men. J Urol. 2004; 172(5 Pt 1):1935-1940.

28. Giuliano F, Kaplan SA, Cabanis MJ, Astruc B. Hemodynamic interaction study between the alphal-blocker alfuzosin and the phosphodiesterase-5 inhibitor tadalafil in middle-aged healthy male subjects. Urology. 2006;67(6):1199-1204.

29. Kaplan SA, Gonzalez RR, Te AE. Combination of alfuzosin and sildenafil is superior to monotherapy in treating lower urinary tract symptoms and erectile dysfunction. Eur Urol. 2007;51(6): 1717-1723.

30. Bechara A, Romano S, Casabé A, et al. Comparative efficacy assessment of tamsulosin vs tamsulosin plus tadalafil in the treatment of LUTS/BPH. Pilot study. J Sex Med. 2008;5(9): 2170-2178.

31. Singh DV, Mete UK, Mandal AK, Singh SK. A comparative randomized prospective study to evaluate efficacy and safety of combination of tamsulosin and tadalafil vs tamsulosin or tadalafil alone in patients with lower urinary tract symptoms due to benign prostatic hyperplasia. J Sex Med. 2014;11(1):187-196.

32. Liguori G, Trombetta C, De Giorgi G, et al. Efficacy and safety of combined oral therapy with tadalafil and alfuzosin: an integrated approach to the management of patients with lower urinary tract symptoms and erectile dysfunction. Preliminary report. J Sex Med. 2009;6(2):544-552.

33. Chung BH, Lee JY, Lee SH, Yoo SJ, Lee SW, Oh CY. Safety and efficacy of the simultaneous administration of udenafil and an alpha-blocker in men with erectile dysfunction concomitant with BPH/LUTS. Int $J$ Impot Res. 2009;21(2):122-128.

34. Casabé A, Roehrborn CG, Da Pozzo LF, et al. Efficacy and safety of the coadministration of tadalafil once daily with finasteride for 6 months in men with lower urinary tract symptoms and prostatic enlargement secondary to benign prostatic hyperplasia. J Urol. 2014;191(3):727-733.

35. Roehrborn CG, McVary KT, Elion-Mboussa A, Viktrup L. Tadalafil administered once daily for lower urinary tract symptoms secondary to benign prostatic hyperplasia: a dose finding study. J Urol. 2008;180(4): $1228-1234$

36. Donatucci CF, Brock GB, Goldfischer ER, et al. Tadalafil administered once daily for lower urinary tract symptoms secondary to benign prostatic hyperplasia: a 1-year, open-label extension study. BJU Int. 2011;107(7):1110-1116.

37. Forgue ST, Phillips DL, Bedding AW, et al. Effects of gender, age, diabetes mellitus and renal and hepatic impairment on tadalafil pharmacokinetics. Br J Clin Pharmacol. 2007;63(1):24-35. 
38. Ring BJ, Patterson BE, Mitchell MI, et al. Effect of tadalafil on cytochrome P450 3A4-mediated clearance: studies in vitro and in vivo. Clin Pharmacol Ther. 2005;77(1):63-75.

39. Weeks JL, Zoraghi R, Beasley A, Sekhar KR, Francis SH, Corbin JD. High biochemical selectivity of tadalafil, sildenafil and vardenafil for human phosphodiesterase 5A1 (PDE5) over PDE11A4 suggests the absence of PDE11A4 cross-reaction in patients. Int J Impot Res. 2005;17(1):5-9.

40. Kloner RA, Hutter AM, Emmick JT, Mitchell MI, Denne J, Jackson G. Time course of the interaction between tadalafil and nitrates. $\mathrm{J} \mathrm{Am}$ Coll Cardiol. 2003;42(10):1855-1860.
41. Goldfischer E, Kowalczyk JJ, Clark WR, et al. Hemodynamic effects of once-daily tadalafil in men with signs and symptoms of benign prostatic hyperplasia on concomitant $\alpha 1$-adrenergic antagonist therapy: results of a multicenter randomized, double-blind, placebo-controlled trial. Urology. 2012;79(4):875-882.

\section{Publish your work in this journal}

The International Journal of General Medicine is an international, peer-reviewed open-access journal that focuses on general and internal medicine, pathogenesis, epidemiology, diagnosis, monitoring and treatment protocols. The journal is characterized by the rapid reporting of reviews, original research and clinical studies across all disease areas.
A key focus is the elucidation of disease processes and management protocols resulting in improved outcomes for the patient.The manuscript management system is completely online and includes a very quick and fair peer-review system. Visit http://www.dovepress.com/ testimonials.php to read real quotes from published authors.

Submit your manuscript here: http://www.dovepress.com/international-journal-of-general-medicine-journal 